FEATURE

Debra Leaker

Office for National Statistics

\title{
Sickness absence from work in the UK
}

$\int$ irect costs of sickness absence to employers include statutory sick pay, expense of covering absence

This article presents sickness absence rates by various personal and labour market characteristics, from the Labour Force Survey, for working-age (men aged 16 to 64 and women aged 16 to 59) employees. It also presents logistic regression analysis, which is a method to combine a range of factors affecting sickness absence to see their effect, and finally looks at other sources of information on sickness absence from work.

In the period July 2007 to June 2008 , around 5.8 million scheduled working days were lost to sickness or injury: this accounted for 1.5 per cent of scheduled working days. Women and those working in the public sector are most likely to be absent from work because of sickness or injury. with temporary staff and lost production. Indirect costs, such as low morale among staff covering for those absent because of sickness and lower customer satisfaction, are harder to measure, but also impact on the overall levels of output. The 2008 Confederation of Business Industry (CBI) report found the direct cost of absence in 2007 was $£ 13.2$ billion, around $£ 517$ for each employee. The CBI estimates that indirect costs added another $£ 263$ for each employee. When these indirect costs are added to the direct costs, the CBI estimates the UK lost $£ 19.9$ billion to absence in 2007.

\section{Labour Force Survey}

The Labour Force Survey (LFS) is a quarterly sample survey of about 53,000 households living at private addresses in the UK, representing about 0.2 per cent of the population. The survey asks respondents for information on their personal circumstances and labour market status. The survey also collects information on whether a respondent took days off because of sickness or injury in the reference week (usually the week before the survey interview). This allows calculation of an estimate of working days lost because of sickness absence in the reference week. It also allows calculation of a sickness absence rate, the proportion of all working-age employees who took at least one day off due to sickness or injury in the reference week. ${ }^{1}$
These rates do not take account of the total duration of a person's sickness absence, as the use of the reference week means the LFS can only measure sickness absence lasting for a maximum of seven days, including those on long-term sick absence.

\section{Trends in sickness absence rates}

Figure 1 shows that sickness absence rates fluctuate throughout the year. They are lowest in July to September and highest in January to March or October to December. Figures presented in the next section combine data from July to September, October to December, January to March and April to June, presenting data from one mid-year to the next.

Figure 2 shows that the sickness absence rate for all employees decreased between the 12 months ending June 2001 and the 12 months ending June 2006. Since this period, sickness absence rates for all working-age employees have remained stable at around 2.5 per cent, which means some 2.5 per cent of working-age employees had at least one day's absence from work in the reference week because of sickness or injury.

Data in the following section are for the period July 2007 to June 2008.

In the twelve months ending June 2008, there were 5.8 million scheduled working days lost to sickness or injury. This accounted for 1.5 per cent of scheduled working days.

Figure 3 shows that the sickness absence rate for women absent from work because of sickness or injury was 2.9 


\section{Figure 1}

\section{Quarterly sickness absence rates of working-age employees}

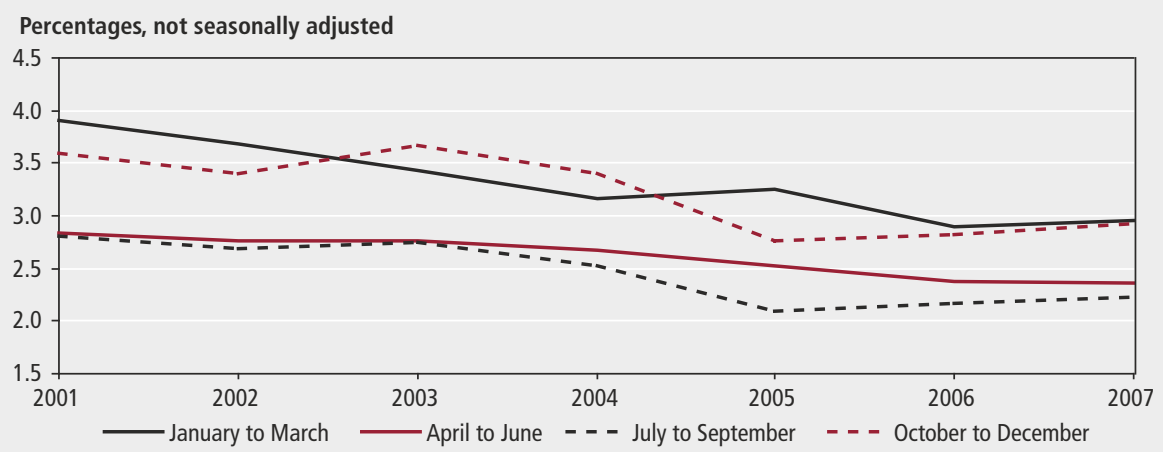

Source: Labour Force Survey

\section{Figure 2}

\section{Sickness absence rates of working-age employees ${ }^{1}$}

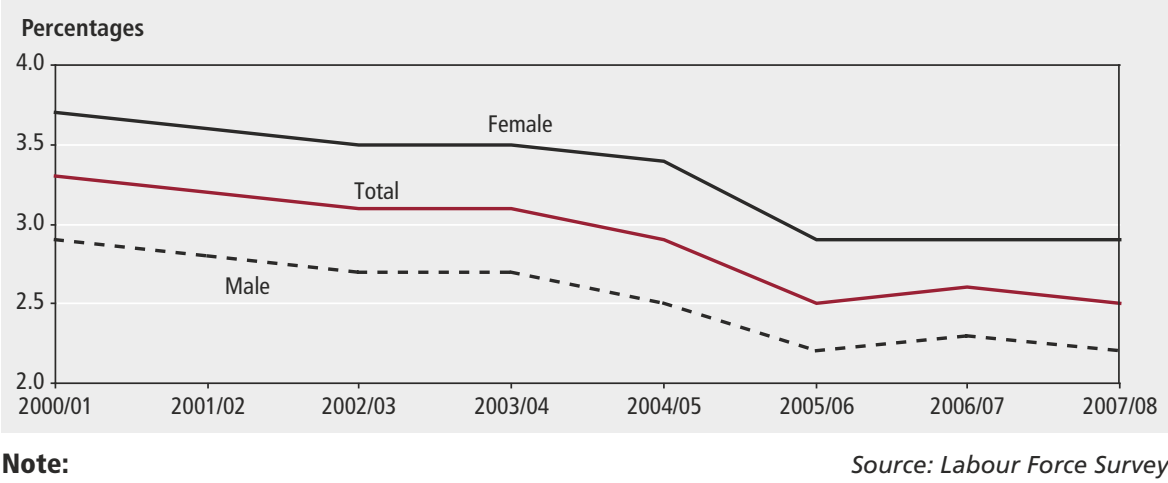

1 July to June for each period.

\section{Figure 3}

\section{Sickness absence rates of working-age employees: by sex and age, July 2007 to June 2008}

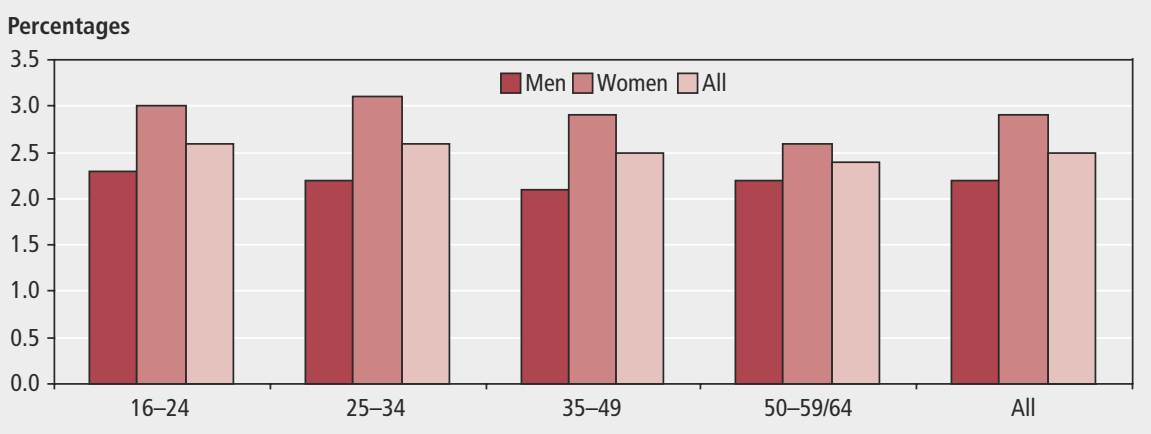

Source: Labour Force Survey

per cent compared with 2.2 per cent for men. Analysis by age shows that younger employees are more likely to take sickness absence than older employees: 2.6 per cent of the 16 to 24 and 25 to 34 age groups were absent from work because of sickness or injury. This compares with 2.5 per cent for 35 to 49 -year-olds and 2.4 per cent for employees aged 50 to 59/64. Among men, those aged 16 to 24 were the most likely to be absent due to sickness (2.3 per cent), whereas for women, those aged 25 to 34 had the highest rate of sickness absence (3.1 per cent).

\section{Personal characteristics}

Around 12.4 per cent of working-age employees classify themselves as disabled, of which 4.6 per cent were absent from work because of sickness or injury. In comparison, only 2.3 per cent of employees who do not classify themselves as disabled were absent from work.

Table 1 shows that the Black/Black British ethnic group has the highest sickness absence rates, at 3.8 per cent. The Asian/Asian British ethnic group has the lowest rates, at 2.3 per cent, while 2.5 per cent of those in the White ethnic group were absent from work in the reference week.

\section{Workplace characteristics}

Table 1 shows that workplaces with fewer than 25 employees have a sickness absence rate of 2.3 per cent, compared with 2.8 per cent for those workplaces with over 500 employees. Recent findings published by the Chartered Institute of Personnel and Development stated that:

smaller organisations typically record lower levels of absence because absence is more disruptive and harder to cover for. Smaller employers are also less likely to provide as generous occupational sick pay schemes as larger employers.

Sickness absence rates in the public sector remain the highest, at 2.9 per cent, compared with 2.4 per cent for those in the private sector. Using the LFS, sickness absence rates in the civil service are 3.5 per cent. As in the Cabinet Office sickness absence report, results from the LFS also show that women and part-timers working in the civil service are most likely to be absent from work due to sickness or injury.

\section{Job tenure}

Sickness absence varies by length of time in post. Those who have worked in the same workplace for more than five years but less than ten have a sickness absence rate of 2.7 per cent. For those who worked in the same workplace for less than three months, the sickness absence rate is 2.3 per cent. It is also 2.3 per cent for those working in the same workplace for more than 20 years.

\section{Occupation}

The LFS classifies occupation by nine major groups, using the 2000 Standard Occupational Classification. Sickness absence rates vary between occupations, from 2.0 per cent for 'managers and senior officials' to 3.1 per cent for 'personal service occupations' and 'administrative and secretarial occupations. Table 2 shows further analysis by detailed occupation breakdown. 'Customer service occupations' (for example, call centre agents/operators) have the highest sickness absence rates, at 4.8 per cent, while 'transport associate professionals' (for example, train drivers) have the lowest, at 0.8 per cent.

\section{Working patterns}

In the LFS, whether a respondent is working full-time is determined by their 
Table 1

Sickness absence rates of working-age employees, July 2007 to June 2008

Percentages

\begin{tabular}{lr}
\hline & Rate \\
\hline Disability & 4.6 \\
Disabled & 2.3 \\
Not disabled & 2.3
\end{tabular}

Ethnicity

White

Mixed

Asian or Asian British

Black or Black British

Chinese

Other

Workplace size

Less than 25

25-49

50-499

500 or more

Total

Sector

Public

Private

Job tenure

Less than three months

Three months but less than six

Six months but less than 12

One year but less than two

Two years but less than five

Five years but less than ten

Ten years but less than 20

20 years or more

Occupation

Managers and senior officials

Professional occupations

Associate professional and technical

Administrative and secretarial occupations

Skilled trades occupations

Personal service occupations

Sales and customer service occupations

Process, plant and machine operatives

Elementary occupations

Full-time/part-time

Full-time

Part-time

Hours worked (including overtime)

Less than 16

$16-30$

$31-45$

Over 45

Income

Less than $\mathrm{f} 300$

$\mathrm{f} 300-£ 399$

$\mathrm{f} 400-£ 499$

$£ 500-£ 599$

$\mathrm{f} 600+$ own assessment and not the number of hours worked. Those working full-time have higher sickness absence rates than part-timers, 2.6 per cent compared with 2.4 per cent. Those working full-time are more likely to be absent from work on a Friday because of sickness or injury while part-timers are more likely to be absent on Wednesdays because of sickness or injury.

Analysis by hours worked (including overtime) shows that those working 16 to 30 hours or 31 to 45 hours per week have the highest sickness absence rates, at 2.7 per cent. In comparison, those working less than 16 hours have sickness absence rates of 1.8 per cent, while 2.1 per cent of those working over 45 hours per week were absent from work.

\section{Sickness absence rates by income}

Table 1 shows that sickness absence rates generally decrease as gross weekly pay increases. Those employees earning between $£ 300$ to $£ 399$ and $£ 400$ to $£ 499$ each week have sickness absence rates of 3.0 per cent while those earning more than $£ 600$ each week have rates of 2.2 per cent. This is consistent with research published by the Cabinet Office which found that those employees of higher grades in the public sector had fewer sick absences than those in lower grades (Cabinet Office 2007).

\section{Statistical modelling of sickness absence}

So far, this article has presented statistics for a variety of personal characteristics of those employees absent from work due to sickness or injury. A statistical technique known as logistic regression creates a model that considers a range of personal characteristics to determine which of these are most associated with employees having at least one day off in the reference week. Modelling looks at all the factors simultaneously to control for those that affect sickness absence rates.

The model introduces control variables for sex, occupation, disability, ethnicity, region, workplace size, sector, working pattern, hours worked, age band and job tenure. These are used to predict whether an individual has had a day off due to sickness or injury in the reference week. The analysis considers employees of working age in April to June 2008.

For each variable within the model, one category was selected as the reference category; this enables comparisons to be made with other categories within that variable. The reference category was usually that with the largest sample size. 
Table 2 Sickness absence rates of working-age employees: by detailed
occupation breakdown, July 2007 to June 2008

\section{Five highest}

721 Customer service occupations

541 Textiles and garment trades

411 Administrative: government and related

342 Design associate professionals

912 Elementary construction occupations

Five lowest

351 Transport associate professionals

241 Legal professionals

542 Printing trades

344 Sports and fitness occupations

117 Protective service officers

Source: Labour Force Survey

Figure 4 shows the impact of personal and labour market characteristics on the likelihood of the respondent being absent from work due to sickness or injury. The bars shaded magenta indicate where a category within a variable is estimated to be significantly different from the reference category at the 5 per cent significance level. As each estimate is drawn from a sample of the population, different samples could give different results. Statistical significance means that, at the 5 per cent significance level, it is 95 per cent certain that the estimated relationship is not due to chance. In the graph, only those variables where there is a significant relationship are shown.

The analysis shows that after controlling for other factors:

- women are 22 per cent more likely to be absent from work in the reference week than men

- those working in the public sector are 22 per cent more likely to be absent than those working in the private sector

- the Black/Black British ethnic group are 51 per cent more likely to be absent than the White ethnic group

- those working less than 16 hours per week are 47 per cent less likely to be absent than those working over 45 hours

- employees aged 16 to 24 are 32 per cent more likely to be absent than those aged 50 to $59 / 64$

- those employees who classify themselves as disabled are almost 2.5 times more likely to be absent than those not disabled

- employees in 'personal service occupations' are 57 per cent more likely to be absent than those in the 'professional occupations'

- those in workplaces with more than 500

\section{Notes}

1 For more information on sickness absence rates, see www.statistics.gov. uk/statbase/product.asp?vlnk=14424

\section{CONTACT}

(凶)elmr@ons.gsi.gov.uk

\section{REFERENCES}

Absence Management, Annual Survey Report 2008, Chartered Institute of Personnel and Development at

www.cipd.co.uk/subjects/hrpract/absence/ absmagmt.htm

Barham C and Leonard J (2002) 'Trends and sources of data on sickness absence', Labour Market Trends 110(4), pp 177-85

Barham C and Begum N (2005) 'Sickness absence from work in the UK', Labour Market Trends 113(4), pp 149-58.

Cabinet Office (2007) 'Civil Service sickness absence 2006-2007' at

www.civilservice.gov.uk/about/statistics/ sickness.asp

Machin A and Millard B (2007)

'Characteristics of public sector workers', Economic \& Labour Market Review 1(5), pp 46-55 and at

www.statistics.gov.uk/cci/article. asp? $\mathrm{id}=1801$

Sickies and Long-Term Absence give employers a headache - CBI/AXA Survey (May 2008) at www.cbi.org.uk/ndbs/press.nsf/ 0363c1f07c6ca12a8025671c00381cc7/ 90ab71d2f4d981da8025744200523b87? OpenDocument

\section{Figure 4}

\section{Impact of various characteristics on the odds of a respondent being absent due to sickness or injury in the reference week}

Percentage difference in the relative odds

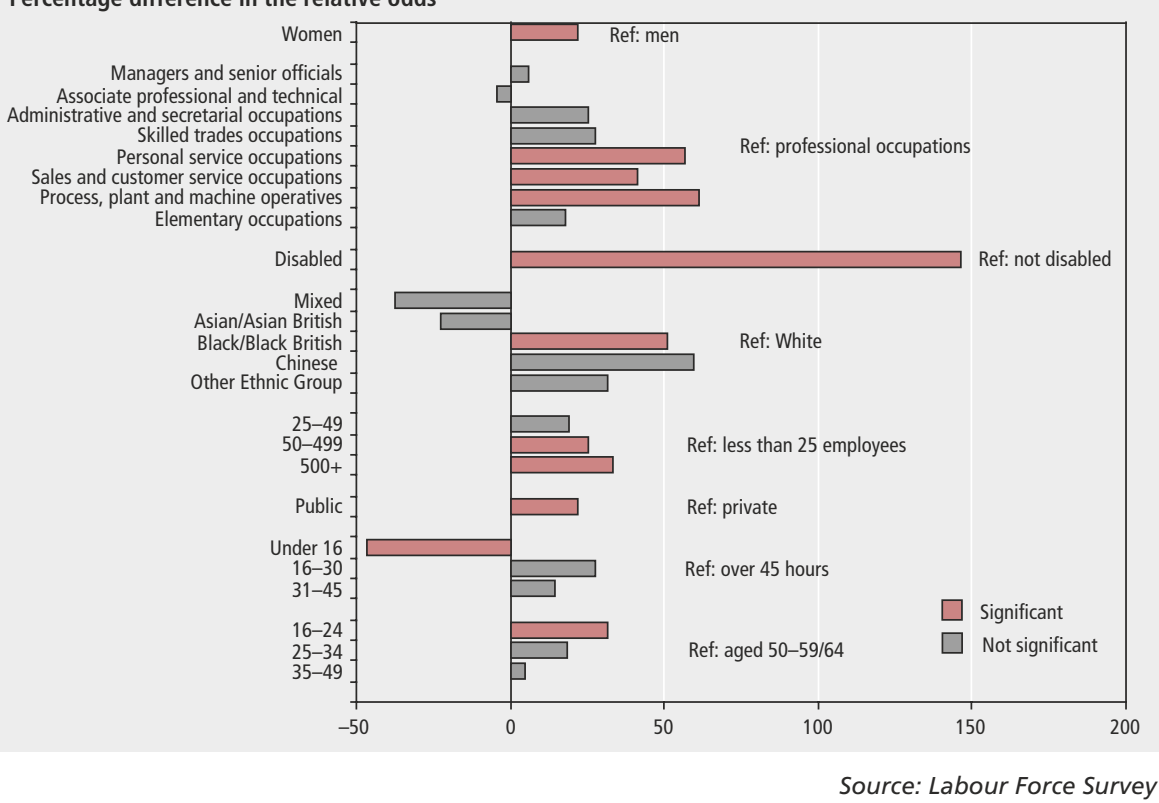




\section{APPENDIX}

Table A1

\section{Other sources of sickness absence data}

\begin{tabular}{|c|c|}
\hline Source & Key findings \\
\hline $\begin{array}{l}\text { Confederation of British } \\
\text { Industry }\end{array}$ & $\begin{array}{l}\text { Analysis based on replies from } 503 \text { companies who together employ more than } 1 \text { million } \\
\text { employees, equivalent to } 3.6 \text { per cent of the UK workforce. }\end{array}$ \\
\hline \multirow[t]{8}{*}{$\begin{array}{l}\text { Absence and labour turnover, } \\
\text { May } 2008\end{array}$} & $\begin{array}{l}\text { In } 2007 \text {, direct cost of absence } \mathrm{f} 13.2 \text { billion or } \mathrm{f} 517 \text { each employee. Indirect costs add } \\
\text { another } \mathrm{f} 263 \text { per employee. Total cost of absence comes to } \mathrm{f} 19.9 \text { billion. }\end{array}$ \\
\hline & Average employee took 6.7 days off sick. \\
\hline & 172 million days lost to sickness absence, 12 per cent thought to be non-genuine. \\
\hline & $\begin{array}{l}5 \text { per cent of absence spells became long-term ( } 20 \text { days or more), accounting for } 40 \text { per cent } \\
\text { of all time lost. }\end{array}$ \\
\hline & $\begin{array}{l}\text { Average absence levels in the public sector stood at } 9 \text { days compared with } 5.8 \text { days in the } \\
\text { private sector. }\end{array}$ \\
\hline & $\begin{array}{l}\text { Organisations that recognised trade unions saw three days' more absence than in non- } \\
\text { unionised workplaces. }\end{array}$ \\
\hline & $\begin{array}{l}\text { Strong regional differences across the UK. North West and Yorkshire and The Humber lost } \\
\text { most days, Southern England the least. }\end{array}$ \\
\hline & $\begin{array}{l}\text { Minor ailments, such as colds, are the most significant cause of short-term absence; back } \\
\text { pain came second. }\end{array}$ \\
\hline
\end{tabular}

Chartered Institute of Personnel Analysis based on replies from 819 UK-based HR professionals in organisations employing and Development more than 2.3 million employees.

Absence measurement and The average sickness absence was 3.5 per cent, or 8.0 working days each employee. management, July 2008 The average annual cost of absence each employee was estimated at $\mathrm{f} 666$. Absence levels in the public sector remain the highest.

Only 40 per cent of respondent organisations monitor the cost of absence.

The main cause of short-term absence for both manual and non-manual workers is minor illness such as colds, flu and stomach upsets.

Smaller organisations typically record lower levels of absence because absence is more disruptive and harder to cover for.

The main causes of long-term absence (four weeks or more) among manual workers are acute medical conditions, followed by back pain, musculoskeletal conditions, stress and mental health problems.

Cabinet Office

Almost 50 per cent of civil servants had no recorded absence in 2006/07 and over three-

Analysis of sickness absence in quarters of the civil service took fewer than five working days off sick.

the civil service, February 2008 Total cost of absence was estimated at $£ 393$ million.

Average working days lost each staff year is 9.63 .

Younger staff have more spells of absence, but these are shorter than for older staff.

Women have more spells of absence than men.

Staff in the lower grades have a tendency to take more spells and longer spells than those at higher grades.

Mental disorders and musculoskeletal accounted for around a third (34 per cent) of all days lost.

For all lengths of absence, there is a trend for spells to end so return to work will be on a Monday. For shorter-term absences, there is a trend for spells to start at the beginning of the week.

Shift workers tended to have proportionally more spells and for these to be longer than for full-time workers. For part-time workers, this pattern was even more pronounced. 